\title{
HOXA10 expression is decreased by testosterone in luteinized granulosa cells in vitro
}

\author{
HONG HE ${ }^{1,2}$, TIAN LI ${ }^{1}$, DELONG YIN ${ }^{3}$, RONG LIU ${ }^{1}$, QIONGHUA CHEN ${ }^{4}$, \\ JI WANG ${ }^{5}$, GANG ZHONG ${ }^{1}$ and DEMIN PU ${ }^{1}$
}

\author{
${ }^{1}$ Department of Obstetrics and Gynecology, Tongji Hospital, Tongji Medical College of Huazhong University \\ of Science and Technology, Wuhan, Hubei 430030; ${ }^{2}$ Department of Obstetrics and Gynecology, The Third Affiliated Hospital \\ of Guangzhou Medical University, Guangzhou, Guangdong 510150; ${ }^{3}$ Department of Orthopedics, Tongji Hospital, \\ Tongji Medical College of Huazhong University of Science and Technology, Wuhan, Hubei 430030; \\ ${ }^{4}$ Department of Obstetrics and Gynecology, Xiamen First Hospital Affiliated to Fujian Medical University, \\ Xiamen, Fujian 361003; ${ }^{5}$ Department of General Surgery, Tongji Hospital, Tongji Medical College \\ of Huazhong University of Science and Technology, Wuhan, Hubei 430030, P.R. China
}

Received February 2, 2012; Accepted April 10, 2012

DOI: $10.3892 / \mathrm{mmr} .2012 .875$

\begin{abstract}
Polycystic ovary syndrome (PCOS) is perhaps the most prevalent endocrine disorder in women of reproductive age, characterized by elevated levels of circulating androgens or clinical manifestations of androgen excess. The specific cytokine profile of PCOS patients is probably related to the lower implantation rate, since follicular fluid appears to function as an embryotrophic agent. For a better understanding of the local regulation of human follicles, the present study investigated the protein expression levels and cellular localization of HOXA10 in granulosa cells (GCs) from women with normal ovarian function undergoing IVF due to their husbands suffering from azoospermia. We demonstrated by immunohistochemical studies that the expression of HOXA10 was mainly localized in the cytoplasm of GCs. Our data indicate that these alterations were associated with changes in the expression of ovarian transcription factors of HOXA10. GC dose-responsive decreases in HOXA10 protein were observed in response to physiological or supraphysiological concentrations $\left(10^{-4}\right.$ to $10^{-7} \mathrm{M}$ ) of testosterone. These data reveal that testosterone may be involved in HOXA10 gene regulation in GCs. Decreased HOXA10 expression in GCs treated with testosterone suggest that this androgen is responsible for the decreased expression of HOXA10 in PCOS patients.
\end{abstract}

Correspondence to: Professor Demin $\mathrm{Pu}$, Department of Obstetrics and Gynecology, Tongji Hospital, Tongji Medical College of Huazhong University of Science and Technology, Wuhan, Hubei 430030, P.R. China

E-mail:pdmtjh@gmail.com

Key words: HOXA10, granulosa cells, testosterone, polycystic ovary syndrome

\section{Introduction}

Polycystic ovary syndrome (PCOS) is perhaps the most prevalent endocrine disorder in women of reproductive age, and the most frequent cause of oligo-anovulation and hyperandrogenism (1-3), both of which have substantial psychological, social and economic consequences $(2,4)$. PCOS is associated with $75 \%$ of all anovulatory disorders causing infertility $(5,6)$. The excess ovarian androgen production is induced by extraovarian factors, including insulin resistance and hyperinsulinemia $(7,8)$. The clinical manifestations and ramifications of this disorder vary with the degree of hyperandrogenism and include a number of metabolic disorders, including insulin resistance, diabetes mellitus, hypertension, dyslipidemia and cardiovascular disease. However, the lack of a clear etiology associated with these syndromes has led to multiple treatments with few effective therapies for infertility $(9,10)$.

Ovarian follicular maturation represents one of the most complex and clinically important developmental processes that takes place throughout the reproductive life of women. During this process, the oocyte and the granulosa cells (GCs) establish mutual interactions and their growth is regulated by complicated molecular mechanisms $(11,12)$. The transcription factors that control these interactions are poorly defined, but may well include clustered homeobox (HOX) genes, which code for families of transcription factors and act at the top of genetic hierarchies (13).

Homeobox genes are evolutionarily conserved and necessary for body axis patterning during embryogenesis. The expression of HOX genes in defined locations along the paramesonephric duct leads to the development of the adult reproductive tract (14). Specifically, HOXA10 is essential for the development of the uterus during organogenesis (15). The persistent expression of HOXA10 in the adult enables the endometrium to retain a developmental plasticity and allows the sequential differentiation of the endometrium during each menstrual cycle (16). HOXA7 and HOX cofactor expression in normal human ovary is temporally 
and spatially specific in GCs and this finding indicates a relationship with GC proliferation $(17,18)$.

However, we are unaware of any study in the literature that has investigated HOXA10 gene expression in granulosa cells. In this study, we examined for the first time the expression patterns of HOXA10 in GCs. In brief, GCs were isolated and identified by immunofluorescence. We evaluated the effect of testosterone on HOX gene expression. Androgen levels are higher in PCOS women with infertility (or recurrent miscarriages) than in normal fertile women (19). Elevated levels of androgens may have a detrimental effect on ovarian function. Androgen receptors are present within the ovarian GCs $(20,21)$. We postulated that hyperandrogenism may result in changes in HOXA10 expression in the GCs. Altered levels of HOXA10 expression, attributable to elevated testosterone, may affect the molecular pathway that leads to ovarian follicular maturation. As a consequence, patients with PCOS may suffer from infertility and early spontaneous miscarriages, despite successful correction of anovulation. Here, we demonstrated that testosterone alters HOXA10 expression in GCs, suggesting further exploration of its effect in PCOS.

\section{Materials and methods}

Patients. The study was performed on patients attending the Reproductive Medicine Center of Tongji Hospital in Wuhan, China. Written informed consent was obtained from each patient; consent forms and protocols were approved by the local ethics committee. Individual follicular fluid samples were collected from 42 women who were undergoing IVF treatment. The population consisted of 42 women with normal ovarian function undergoing IVF-ET due to their husbands suffering from azoospermia. The mean age was $27.5 \pm 2.8$ years (range, 25-34), and mean BMI was $19.11 \pm 1.12 \mathrm{~kg} / \mathrm{m}^{2}$ (range, 16.01-23.58). They had regular menstrual cycle lengths between 25-35 days. Ovulation was documented in the luteal phase prior to the study with serum progesterone levels above $10 \mathrm{ng} / \mathrm{ml}$. Clinical and laboratory manifestations showed no hyperandrogenism, and B super-monitoring of ovulation in the ovary was normal. All subjects were healthy, had been taking no medications for at least 3 months prior to the study, and had normal TSH and PRL levels.

Cell culture. The pooled clear follicular fluid (35 $\mathrm{ml}$ obtained from 10-18 different follicles) from each individual patient was centrifuged at $2000 \mathrm{rpm}$ for $10 \mathrm{~min}$ at room temperature. The GC pellet was suspended in PBS solution (Hyclone Laboratories) (1:1 ratio) and layered by gentle pipetting onto a $0.5-\mathrm{ml}$ Ficoll plaque (Amersham, Arlington Heights, IL, USA) and centrifuged at $2000 \mathrm{rpm}$ for $20 \mathrm{~min}$ to remove red blood cells. The luteinized GCs were maintained in DMEM-F12 (Hyclone Laboratories) with EDTA (6.8 mM), HEPES (10 mM), 20\% fetal bovine serum, penicillin, streptomycin and ITS. Cells were then treated for 6 or $48 \mathrm{~h}$ with hormones or pharmacologic agents. To generate a dose-response curve, testosterone (T) was used at a final concentration of $1 \times 10^{-8}$ to $1 \times 10^{-4} \mathrm{M}$. Estradiol $\left(\mathrm{E}, 5 \times 10^{-8} \mathrm{M}\right)$ and progesterone $\left(\mathrm{P}, 1 \times 10^{-6} \mathrm{M}\right)$ were used at approximately maximal physiological concentrations, at which we previously demonstrated alterations in HOXA10 gene expression in endometrium cells $(22,23)$.
Confocal microscopy imaging. For immunofluorescence staining, $1 \times 10^{4}$ cells were seeded on glass coverslips $(13 \mathrm{~mm}$ diameter). After fixation with $4 \%$ paraformaldehyde in PBS, cell membranes were permeabilized with $0.2 \%$ Triton X-100 in PBS, and nonspecific binding sites were blocked with 5\% BSA in PBS. Treatment with the first antibody was performed at $4^{\circ} \mathrm{C}$ overnight (FSH receptor; Santa Cruz, Santa Cruz CA). Afterwards, the cells were washed three times with cold PBS and incubated with $\mathrm{Cy} 3$-conjugated $\mathrm{IgG}$ diluted 1:50 in PBS for $30 \mathrm{~min}$ at room temperature. Nuclei were stained for $5 \mathrm{~min}$ at room temperature with DAPI. Cells were rinsed with PBS and were observed by confocal microscopy (Olympus, Japan).

Immunohistochemistry. After a 2-day culture, immunocytochemistry was performed in GCs. Briefly, after fixation, peroxidase treatment and serum blocking, GCs were incubated overnight at $4^{\circ} \mathrm{C}$ with a primary rabbit polyclonal antibody against HOXA10 (Abcam). After washing in PBS, GCs were incubated for $30 \mathrm{~min}$ at $37^{\circ} \mathrm{C}$ with biotinylated goat anti-rabbit IgG antibody and then avidin-biotin-peroxidase complex. The color reaction was performed using stable DAB solution for $5 \mathrm{~min}$, as described previously (24). The nucleus was then stained with haematoxylin or $1 \mathrm{mM}$ Hoechst 33342 (Sigma) for $10 \mathrm{~min}$. The samples were examined by inverted microscopy (Leica, Heerbrugg, Switzerland) with an ultraviolet light filter. The morphology of GCs cultured in different T, P, E, T+P, T+E concentrations was recorded with an Olympus inverted microscope at $48 \mathrm{~h}$.

Western blot analysis. Cells were harvested, and the expression levels of total HOXA10 were analyzed. Cell extracts $(50 \mu \mathrm{g})$ were electrophoresed on a 10\% SDS-PAGE and transferred to a polyvinylidene difluoride membrane. The membrane was blocked for $1 \mathrm{~h}$ at room temperature using $5 \%$ nonfat milk in Tris-buffered saline [10 mM Tris, $150 \mathrm{mM}$ phosphate-buffered saline (PBS), $\mathrm{pH} 8.0$ ] containing $0.05 \%$ Tween 20. Membranes were incubated with diluted primary antibodies (HOXA10, 1:800; $\beta$-actin 1:1,000) at $4^{\circ} \mathrm{C}$ overnight. They were then incubated with secondary antibodies (1:1000 dilution), and immunoreactive bands were visualized with alkaline phosphatase and BCIP/NBT staining. All blots were repeated three times.

Data analysis. Data are expressed as the means \pm SEM. Protein quantification from western immunoblotting was performed via normalization to $\beta$-actin for each gel. Statistical analyses were performed using SPSS 13.0 statistical software. Differences between groups were compared using the Student's t-test. $\mathrm{P}<0.05$ was considered to indicate a statistically significant difference.

\section{Results}

The FSH receptor was used in this study to isolate GCs, as it is a potent cell marker of GCs. Fig. 1 shows the expression of FSH receptor (FSHR) in GCs. The strongest positive immunostaining of FSHR was observed in GCs. HOXA10 expression is regulated by testosterone in GCs. Endometrial HOX gene expression has been shown to be regulated by 

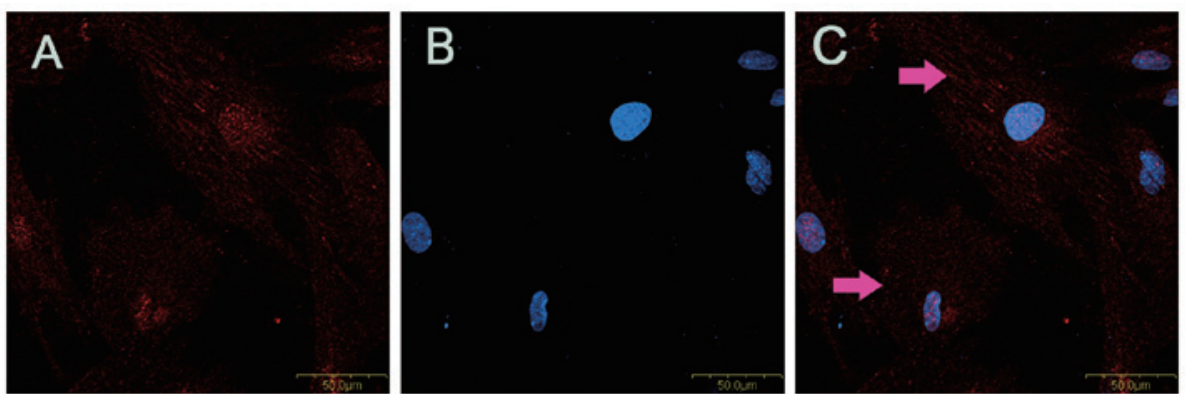

Figure 1. Expression of FSH receptor in GCs. The strongest positive immunostaining of FSHR was observed in GCs (Fig. 1C). GCs, granulosa cells; FSHR, follicle-stimulating hormone receptor.

A
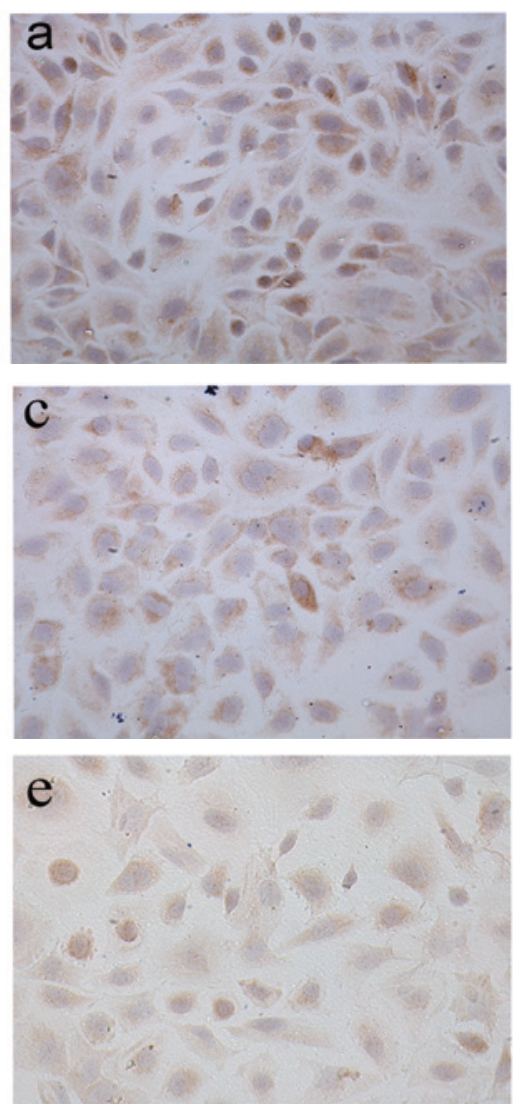

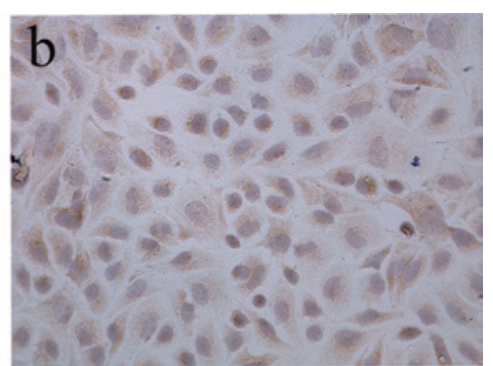

B
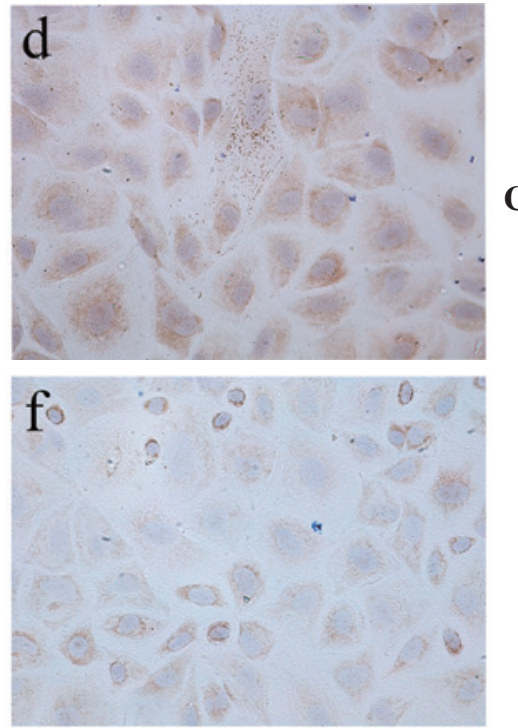

C control $\quad 10^{-8} \quad 10^{-7} \quad 10^{-6} \quad 10^{-5} \quad 10^{-4}$

HOXA10

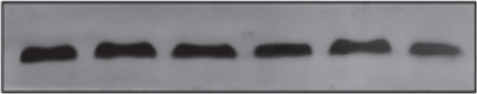

$\beta$-actin

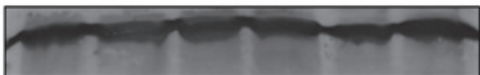

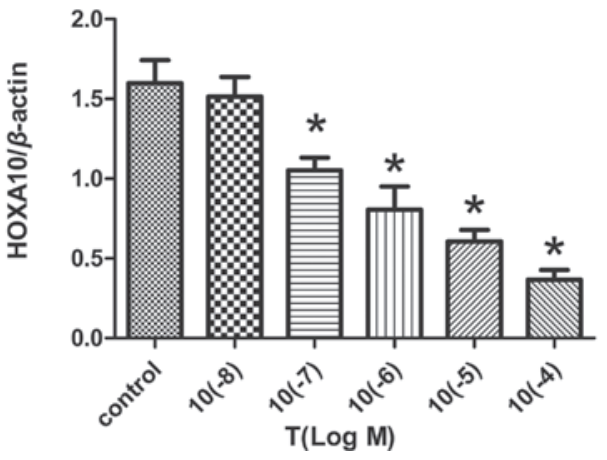

Figure 2. Effect of testosterone on HOXA10 expression. Granulosa cells (GCs) were treated for $24 \mathrm{~h}$ with either testosterone or control. (A) Representative immunocytochemical analysis: (a) control; (b) testosterone at $10^{-8} \mathrm{M}$; (c) $10^{-7} \mathrm{M}$; (d) $10^{-6} \mathrm{M}$; (e) $10^{-5} \mathrm{M}$; (f) $10^{-4} \mathrm{M}$; the expression of HOXA10 was mainly localized in the cytoplasm of GCs. (B) Representative western blot analysis. HOXA10 expression was decreased after treatment for $6 \mathrm{~h}$ with testosterone at $10^{-5} \mathrm{M}[\mathrm{T} 10(-5)]$, but not at $10^{-8} \mathrm{M}$ [T10(-8)]. At $24 \mathrm{~h}$, HOXA10 expression remained decreased after treatment with $10^{-6} \mathrm{M}$ testosterone. (C) Quantification and normalization of HOXA10 protein levels after testosterone treatment. Testosterone concentration ranged from $10^{-4}$ to $10^{-8} \mathrm{M}$. HOXA10 expression is decreased after treatment for $6 \mathrm{~h}$ with testosterone at $10^{-5} \mathrm{M}[\mathrm{T} 10(-5)]$, but not at $10^{-8} \mathrm{M}[\mathrm{T} 10(-8)]$. At $24 \mathrm{~h}$, HOXA10 expression remained decreased after treatment with $10^{-6} \mathrm{M}[\mathrm{T} 10(-6)]$ testosterone. A dose-responsive decrease in normalized HOXA10 protein levels was observed. All experiments were repeated in triplicate. Error bars, SEM; "statistically different from control $(\mathrm{P}<0.05)$.

estrogen and progesterone $(22,23)$. To determine whether HOXA10 is expressed in GCs and is regulated by androgens, HOXA10 expression was measured in GCs following treatment with testosterone. Fig. 2 shows the expression of HOXA10 was mainly localized in the cytoplasm of GCs. HOXA10 expression decreased following treatment with testosterone in a dose-responsive manner in GCs. Testosterone concentrations at or less than $10^{-8} \mathrm{M}$ produced no discernible effect; however, at $10^{-7} \mathrm{M}$, a significant decrease in HOXA10 protein expression was observed. A further decrease in HOXA10 expression was observed with supraphysiologic treatments $\left(10^{-6}\right.$ to $\left.10^{-4} \mathrm{M}\right)$. The decrease in HOXA10 protein expression persisted $24 \mathrm{~h}$ after testosterone $\left(10^{-6} \mathrm{M}\right)$ treatment. As previously demonstrated, treatment of GCs with estradiol and progesterone leads to increased HOXA10 protein expression. Fig. 3 shows the effect of simultaneous treatment with estradiol $\left(5 \times 10^{-8} \mathrm{M}\right)$ and testosterone $\left(10^{-6} \mathrm{M}\right)$. Concomitant use of estradiol and testosterone resulted in decreased HOXA10 expression $(\mathrm{P}<0.05)$. Fig. 4 demonstrates the effect of simultaneous treatment with progesterone and testosterone (progesterone, 
A

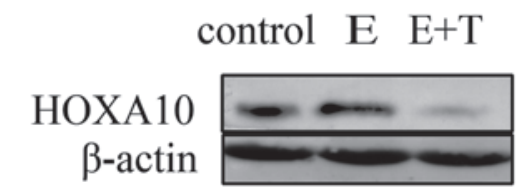

B

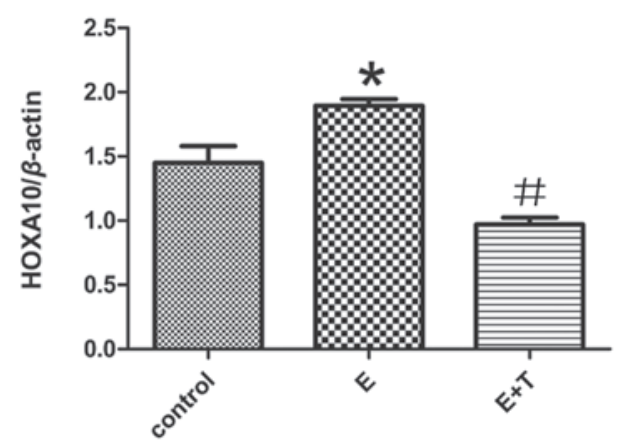

Figure 3. Testosterone reverses the effects of estradiol on HOXA10 expression. Granulosa cells were treated with either control, 17-estradiol $\left(5 \times 10^{-8} \mathrm{M}\right)$, or the combination of estradiol and testosterone $\left(10^{-6} \mathrm{M}\right)(\mathrm{E}+\mathrm{T})$. Testosterone prevents the estradiol-induced rise in HOXA10 protein. Error bars, SEM; "statistically different from control $(\mathrm{P}<0.05)$; "statistically different from estradiol treatment $(\mathrm{P}<0.05)$.

$10^{-6} \mathrm{M}$; testosterone, $\left.10^{-6} \mathrm{M}\right)$. HOXA10 expression is decreased after simultaneous progesterone and testosterone treatment $(\mathrm{P}<0.05)$. Testosterone blocked the expected estradiol- or progesterone-induced increase in HOXA10 protein.

\section{Discussion}

The importance of local growth factors for the modulation of follicular cell function, regarding cell proliferation and steroidogenesis $(25,26)$, is becoming increasingly evident. However, there remains a lack of knowledge concerning various growth factors and their interactions in the follicle throughout follicle development. A variety of methods have been used in attempts to develop culture systems for GCs in many species, such as the rat (27), porcine (28), sheep (29) and bovine (30). To the best of our knowledge, no report has been published using human ovarian GCs as an in vitro model. For a better understanding of the local regulation of human follicles, the present study investigated the protein expression levels and cellular localization of HOXA10 in GCs from women with normal ovarian function undergoing IVF. In the present study, we confirmed the presence of HOXA10 in mammalian ovaries. We demonstrated by immunohistochemical studies that the expression of HOXA10 was mainly localized in the cytoplasm of GCs. Our data reveal that these alterations are associated with changes in the expression of ovarian transcription factors of HOXA10. The dose-responsive decreases in HOXA10 protein in GCs were observed in response to physiological or supraphysiological concentrations $\left(10^{-4}\right.$ to $\left.10^{-7} \mathrm{M}\right)$ of testosterone. These data show that testosterone may be involved in HOXA10 gene regulation in ovarian GCs. Decreased HOXA10 expression in GCs treated with testosterone suggest that this androgen is responsible for the decreased expression of HOXA10 in PCOS patients.
A

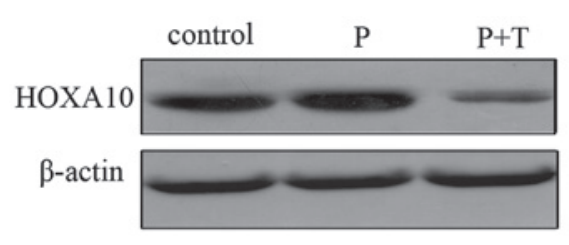

B

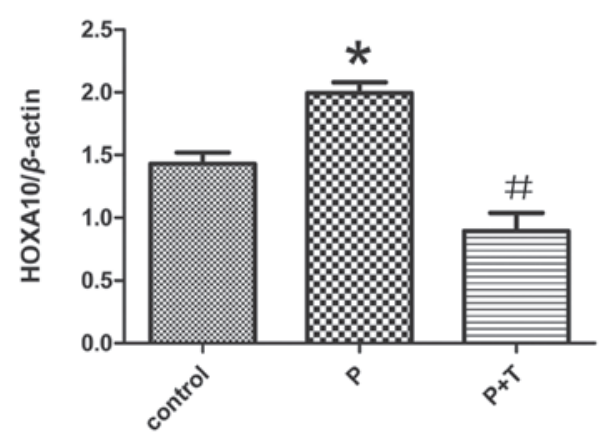

Figure 4. Testosterone reverses the effect of progesterone on HOXA10 expression. Granulosa cells were treated with either control, progesterone $\left(\mathrm{P}, 10^{-6} \mathrm{M}\right)$, or the combination of progesterone and testosterone $(\mathrm{P}+\mathrm{T})$. Testosterone prevents the progesterone-induced rise in HOXA10 protein. Error bars, SEM; "statistically different from control $(\mathrm{P}<0.05)$; " statistically different from progesterone treatment $(\mathrm{P}<0.05)$.

PCOS is perhaps the most common endocrinopathy, affecting approximately $5 \%$ of women in developed countries; it is a common cause of anovulation and infertility, characterized by elevated levels of circulating androgens or clinical manifestations of androgen excess $(31,32)$. The chronic anovulation and infertility is often successfully treated in PCOS; however, resultant successful pregnancy rates are lower than expected $(33,34)$. Recurrent miscarriage is also common in women with PCOS (18-20). The mechanism by which hyperandrogenemia could be linked to increased miscarriage risk is not known. The specific cytokine profile of PCOS patients is likely to be related to the lower implantation rate, since follicular fluid appears to function as an embryotrophic agent $(35,36)$. Certain studies have revealed higher levels of testosterone in the follicular fluid of patients with PCOS $(37,38)$. Hyperandrogenism in PCOS may proceed via dysregulated paracrine/endocrine control of androgen synthesis (37), or result from adrenal androgen excess $(39,40)$. Intraovarian androgens have been found to promote GC proliferation and inhibit GC apoptosis in PCOS patients, particularly in small follicles whose GCs are rich in androgen receptors $(35,36)$, indicating that androgens may have a crucial effect on GC development, and intraovarian androgen may play an important role in the pathogenesis of PCOS via regulating early follicle growth. In this study, we observed that excess androgen decreased the expression of the examined HOXA10 genes in GCs, which suggests that androgenic regulation of these genes may specifically contribute to folliculogenesis. Treatment of primary myometrial cell cultures (41) with testosterone decreases HOXA10 expression in vitro, paralleling the expression observed in GCs.

Testosterone is a novel negative regulator of ovarian HOXA10 expression. Testosterone-induced ovarian dysfunction may contribute to diminished reproductive success, including a decreased implantation and increased miscarriage 
rate. Therapies aimed at correcting hyperandrogenism may be necessary to improve endometrial receptivity and egg quality; ovulation induction alone may not provide optimal treatment. Taken together, these observations may explain the paradox of poor reproductive outcomes in women with PCOS despite correction of ovulatory defects. However, in vitro, testosterone at $10^{-6} \mathrm{M}$ significantly decreased the HOXA10 protein in GCs. Several lines of evidence suggest an important role for the homeodomain protein HOXA10 in regulating oogenesis and folliculogenesis. Treatment of primary myometrial cell cultures (41) with testosterone decreases HOXA10 expression in vitro, paralleling the expression seen in GCs. Further research is required to explore whether there are significant differences in HOXA10 protein levels between the patients with PCOS and controls.

\section{Acknowledgements}

This work was supported in part by a grant from the National Natural Science Foundation of China (No. 81000240).

\section{References}

1. Carmina E, Rosato F, Janni A, Rizzo M and Longo RA: Extensive clinical experience: relative prevalence of different androgen excess disorders in 950 women referred because of clinical hyperandrogenism. J Clin Endocrinol Metab 91: 2-6, 2006.

2. Ehrmann DA: Polycystic ovary syndrome. N Engl J Med 352: 1223-1236, 2005.

3. Beloosesky R, Gold R, Almog B, et al: Induction of polycystic ovary by testosterone in immature female rats: modulation of apoptosis and attenuation of glucose/insulin ratio. Int $\mathrm{J}$ Mol Med 14: 207-215, 2004.

4. Azziz R, Marin C, Hoq L, Badamgarav E and Song P: Health care-related economic burden of the polycystic ovary syndrome during the reproductive life span. J Clin Endocrinol Metab 90: 4650-4658, 2005.

5. Adams J, Polson DW and Franks S: Prevalence of polycystic ovaries in women with anovulation and idiopathic hirsutism. $\mathrm{Br}$ Med J (Clin Res Ed) 293: 355-359, 1986.

6. Homburg R: Polycystic ovary syndrome - from gynaecological curiosity to multisystem endocrinopathy. Hum Reprod 11: 29-39, 1996.

7. Cupisti S, Giltay EJ, Gooren LJ, et al: The impact of testosterone administration to female-to-male transsexuals on insulin resistance and lipid parameters compared with women with polycystic ovary syndrome. Fertil Steril 94: 2647-2653, 2010.

8. Park JM, Lee EJ, Ramakrishna S, Cha DH and Baek KH: Association study for single nucleotide polymorphisms in the CYP17A1 gene and polycystic ovary syndrome. Int J Mol Med 22: 249-254, 2008.

9. Morin-Papunen LC, Duleba AJ, Bloigu A, Jarvelin MR, Saikku P and Pouta A: Chlamydia antibodies and self-reported symptoms of oligo-amenorrhea and hirsutism: a new etiologic factor in polycystic ovary syndrome? Fertil Steril 94: 1799-1804, 2010.

10. Smith CA and Carmady B: Acupuncture to treat common reproductive health complaints: An overview of the evidence. Auton Neurosci 157: 52-56, 2010.

11. Vanderhyden B: Molecular basis of ovarian development and function. Front Biosci 7: d2006-d2022, 2002.

12. Juengel JL and McNatty KP: The role of proteins of the transforming growth factor-beta superfamily in the intraovarian regulation of follicular development. Hum Reprod Update 11: 143-160, 2005.

13. Veraksa A, Del CM and McGinnis W: Developmental patterning genes and their conserved functions: from model organisms to humans. Mol Genet Metab 69: 85-100, 2000.

14. Taylor HS, Vanden Heuvel GB and Igarashi P: A conserved Hox axis in the mouse and human reproductive system: late establishment and persistent expression of the Hoxa cluster genes. Biol Reprod 57: 1338-1345, 1997.
15. Block K, Kardana A, Igarashi P and Taylor HS: In utero diethylstilbestrol (DES) exposure alters Hox gene expression in the developing mullerian system. FASEB J 14: 1101-1108, 2000.

16. Bagot CN, Troy PJ and Taylor HS: Alteration of maternal Hoxa10 expression by in vivo gene transfection affects implantation. Gene Ther 7: 1378-1384, 2000.

17. Ota T, Asahina H, Park SH, et al: HOX cofactors expression and regulation in the human ovary. Reprod Biol Endocrinol 6: 49, 2008.

18. Ota T, Choi KB, Gilks CB, Leung PC and Auersperg N: Cell type- and stage-specific changes in HOXA7 protein expression in human ovarian folliculogenesis: possible role of GDF-9. Differentiation 74: 1-10, 2006.

19. Okon MA, Laird SM, Tuckerman EM and Li TC: Serum androgen levels in women who have recurrent miscarriages and their correlation with markers of endometrial function. Fertil Steril 69: 682-690, 1998.

20. Chadha S, Rao BR, Slotman BJ, van Vroonhoven CC and van der Kwast TH: An immunohistochemical evaluation of androgen and progesterone receptors in ovarian tumors. Hum Pathol 24: 90-95, 1993.

21. Yoshimura Y, Chang C, Okamoto T and Tamura T: Immunolocalization of androgen receptor in the small, preovulatory, and postovulatory follicles of laying hens. Gen Comp Endocrinol 91: 81-89, 1993

22. Cermik D, Selam B and Taylor HS: Regulation of HOXA-10 expression by testosterone in vitro and in the endometrium of patients with polycystic ovary syndrome. J Clin Endocrinol Metab 88: 238-243, 2003.

23. Taylor HS, Arici A, Olive D and Igarashi P: HOXA10 is expressed in response to sex steroids at the time of implantation in the human endometrium. J Clin Invest 101: 1379-1384, 1998.

24. Durlej M, Duda M, Knapczyk K and Slomczynska M: Effects of transferrin on aromatase activity in porcine granulosa cells in vitro. Folia Histochem Cytobiol 46: 423-428, 2008.

25. Spicer LJ, Aad PY, Allen DT, Mazerbourg S, Payne AH and Hsueh AJ: Growth differentiation factor 9 (GDF9) stimulates proliferation and inhibits steroidogenesis by bovine theca cells: influence of follicle size on responses to GDF9. Biol Reprod 78: 243-253, 2008

26. Spicer LJ, Aad PY, Allen D, Mazerbourg S and Hsueh AJ: Growth differentiation factor-9 has divergent effects on proliferation and steroidogenesis of bovine granulosa cells. J Endocrinol 189: 329-339, 2006.

27. Abramovich D, Irusta G, Parborell F and Tesone M: Intrabursal injection of vascular endothelial growth factor trap in eCGtreated prepubertal rats inhibits proliferation and increases apoptosis of follicular cells involving the PI3K/AKT signaling pathway. Fertil Steril 93: 1369-1377, 2010.

28. Sirotkin AV: Effect of two types of stress (heat shock/high temperature and malnutrition/serum deprivation) on porcine ovarian cell functions and their response to hormones. J Exp Biol 213: 2125-2130, 2010.

29. McNatty KP, Heath DA, Hudson NL, et al: The conflict between hierarchical ovarian follicular development and superovulation treatment. Reproduction 140: 287-294, 2010.

30. Maillard V, Uzbekova S, Guignot F, et al: Effect of adiponectin on bovine granulosa cell steroidogenesis, oocyte maturation and embryo development. Reprod Biol Endocrinol 8: 23, 2010.

31. Homburg R: Polycystic ovary syndrome. Best Pract Res Clin Obstet Gynaecol 22: 261-274, 2008.

32. Knochenhauer ES, Key TJ, Kahsar-Miller M, Waggoner W, Boots LR and Azziz R: Prevalence of the polycystic ovary syndrome in unselected black and white women of the southeastern United States: a prospective study. J Clin Endocrinol Metab 83: 3078-3082, 1998.

33. Farhi J, Orvieto R, Gavish $\mathrm{O}$ and Homburg R: The association between follicular size on human chorionic gonadotropin day and pregnancy rate in clomiphene citrate treated polycystic ovary syndrome patients. Gynecol Endocrinol 26: 546-548, 2010.

34. Orvieto R, Meltcer S, Homburg R, Nahum R, Rabinson J and Ashkenazi J: What is the preferred GnRH analogue for polycystic ovary syndrome patients undergoing controlled ovarian hyperstimulation for in vitro fertilization? Fertil Steril 91: 1466-1468, 2009.

35. Ortega HH, Salvetti NR and Padmanabhan V: Developmental programming: prenatal androgen excess disrupts ovarian steroid receptor balance. Reproduction 137: 865-877, 2009.

36. Sen A and Hammes SR: Granulosa cell-specific androgen receptors are critical regulators of ovarian development and function. Mol Endocrinol 24: 1393-1403, 2010. 
37. Volpe A, Coukos G, D'Ambrogio G, Artini PG and Genazzani AR Follicular fluid steroid and epidermal growth factor content, and in vitro estrogen release by granulosa-luteal cells from patients with polycystic ovaries in an IVF/ET program. Eur J Obstet Gynecol Reprod Biol 42: 195-199, 1991.

38. Ledee-Bataille N, Lapree-Delage G, Taupin JL, et al: Follicular fluid concentration of leukaemia inhibitory factor is decreased among women with polycystic ovarian syndrome during assisted reproduction cycles. Hum Reprod 16: 2073-2078, 2001.

39. Loughlin T, Cunningham S, Moore A, Culliton M, Smyth PP and McKenna TJ: Adrenal abnormalities in polycystic ovary syndrome. J Clin Endocrinol Metab 62: 142-147, 1986.
40. Kumar A, Woods KS, Bartolucci AA and Azziz R: Prevalence of adrenal androgen excess in patients with the polycystic ovary syndrome (PCOS). Clin Endocrinol (Oxf) 62: 644-649, 2005.

41. Cermik D, Karaca M and Taylor HS: HOXA10 expression is repressed by progesterone in the myometrium: differential tissuespecific regulation of HOX gene expression in the reproductive tract. J Clin Endocrinol Metab 86: 3387-3392, 2001. 